Research Article

\title{
Field Test Study of the Artificial Ground-Freezing Method Subsurface Excavation Construction of Watered Sandy Stratum in Collapsible Loess Area
}

\author{
Yuan Mei, ${ }^{1,2}$ Liangjie Zhao $\mathbb{D}^{1,2}$ Xueyan Wang, ${ }^{3}$ Dongbo Zhou, ${ }^{1,2}$ Tong Yang, ${ }^{1,2}$ \\ Yuanying Liu, ${ }^{1,2}$ and Hang Gong ${ }^{1,2}$ \\ ${ }^{1}$ College of Civil Engineering, Xi'an University of Architecture and Technology, Xi'an, Shaanxi 710055, China \\ ${ }^{2}$ Shaanxi Key Lab of Geotechnical and Underground Space Engineering, Xi'an University of Architecture and Technology, \\ Xi'an, Shaanxi 710055, China \\ ${ }^{3}$ School of Urban Planning and Municipal Engineering, Xi'an Polytechnic University, Xi'an 710048, Shaanxi, China
}

Correspondence should be addressed to Liangjie Zhao; zljwyg1995@xauat.edu.cn

Received 6 November 2020; Revised 4 December 2020; Accepted 11 December 2020; Published 29 December 2020

Academic Editor: Junping Ren

Copyright (c) 2020 Yuan Mei et al. This is an open access article distributed under the Creative Commons Attribution License, which permits unrestricted use, distribution, and reproduction in any medium, provided the original work is properly cited.

\begin{abstract}
Saturated sandy stratum often makes tunnel excavation exceedingly difficult owing to its high water content. The artificial groundfreezing (AGF) method is an effective way to reduce the construction risks in such stratum; however, the AGF mechanism in the saturated sandy stratum of a collapsible loess area still lacks sufficient research. Based on field tests and numerical simulations, this study investigates the regularity of the temperature development, frost heave, and thaw subsidence distribution during the cross passage construction of a saturated sandy stratum in a collapsible loess area, using the AGF method. The results showed that the inward development rate of the frozen soil wall in the saturated sandy stratum was faster than its outward development rate. The gradient of the soil cooling curve was positively related to the longitudinal depth of the cross passage. The thickness of the frozen soil wall calculated by the slowest development rate of the frozen soil was conservative. The application of the pressure relief hole was beneficial to the release of the frost-heaving force and the control of the frost-heaving displacement. The pressure gauge pressure increase could be used as an identifier for the closure of a frozen soil wall. After excavation, the inner wall of the cross passage moved toward the inner space of the passage.
\end{abstract}

\section{Introduction}

Underground water creates serious safety risks in the excavation construction of a saturated sandy stratum. The question of how best to carry out construction in a saturated sandy stratum, safely, is a fundamental one in this kind of project. The artificial ground-freezing (AGF) method involves freezing soil moisture through artificial refrigeration technology so that the soil becomes a high-strength frozensoil layer. The AGF method also has excellent reinforcement and water-sealing effects. The strength of different parts of the frozen-soil layer can be adjusted according to construction requirements, and it is a suitable method for any loose rock soil layer with a moisture content exceeding $10 \%$, but particularly in water-rich soils [1]. However, in the use of AGF, insufficient cooling, flowing water, or the influence of external heat sources can lead to the degradation of the frozen soil curtain, which increases the construction risk. Similarly, if the soil frost heave and thaw settlement caused by AGF is not properly controlled, the surrounding environment can be damaged, adversely affecting the building structure. Therefore, it is essential to study the temperature, displacement, and mechanical properties of the soil during AGF-based construction.

Hu et al. [2] compared the freezing effects of four soil materials through finite-element analysis, and they found cement-admixed sandy soil to be the most favorable material for freezing. Liu et al. [3] established through laboratory tests 
that $60 \%$ water saturation was the critical saturation level of clay-bearing red sandstone, and with increasing freeze-thaw cycles, the freeze-thaw damage increased rapidly too. Fan et al. [4] found that with increasing freeze-thaw cycles, the static and dynamic mechanical properties of dried sandstone and saturated sandstone decreased, but the uniaxial compressive strength and dynamic strength of dried sandstone were greater than those of saturated sandstone, while its elastic modulus and dynamic energy absorption capacity were lower than those of saturated sandstone. Similarly, with increasing freeze-thaw cycles, the integrity of the loess sample decreased [5], which led to a decline in its bearing capacity. In addition, Xu et al. $[6,7]$ found that cohesion of the loess varied with the cycles of freeze and thaw until a residual value was reached while the internal friction angle has little change.

Ding et al. [8] conducted an experimental study on the microstructure of thawed soil after the AGF-based construction of a metro. They pointed out that the temperature gradient curve of artificially frozen soil is steeper than that of seasonally frozen soil because it needs to provide enough cold source during the formation process to ensure that the soil is frozen in a short time. Han et al. [9] used a new type of antifreezing soil pressure gauge to measure the frost-heaving pressure of segments in the construction of an AGF-based cross passage. They found that the maximum frost-heaving pressure of segments was approximately $0.2 \mathrm{MPa}$, far less than $1.5 \sim 1.8 \mathrm{MPa}$ previously measured within the frozen soil. $\mathrm{Hu}$ et al. [10] measured a large-diameter shield tunnel strengthened by cement soil combined with AGF in the field and proposed changed rules of the frost-heaving displacement of cement soil in construction using the AGF method. Pimentel et al. [11] simulated three applications of AGF using code (FREEZE) which was established for simulating coupled thermohydraulic processes-the practicality of FREEZE was verified. Vitel et al. [12] developed a heat transfer model suitable for the application of AGF and proposed that the calculation speed could be greatly improved by simplifying the 2-D axisymmetric heat transfer problem into a 1-D model, coupling a 1-D vertical calculation with $1-\mathrm{D}$ radial calculations at different depths underground-its assumptions being identical to the 2-D problem, except that vertical heat transfers are negligible. Zhao et al. [13] used refrigeration units and air-cooling radiators to cool the circulating medium, combining natural cold resources with AGF to freeze the underground soil. Research shows that the method reduced running costs and power by 52 and $53.4 \%$, respectively, compared with conventional methods. Song et al. [14] established a 3-D finiteelement model of the temperature field for AGF construction in soft ground-the detailed distribution of the freezing temperature field was established by considering the ground temperature, surface convection, and latent heat of phase change. Fan and Yang [15] carried out temperature measurements for AGF-based construction of a cross passage in the silted ground and proposed their corresponding thermal transfer model.

In short, there are many successes in the repeated freezethaw tests of soil materials and the application of AGF in tunnel construction, but there are no reports on the application of AGF in the construction of saturated sandy stratum in collapsible loess areas $[16,17]$. The effect of the application of AGF in the sand layers of this region is not yet clear, particularly the temperature development of the frozen soil wall and the displacement of the frozen soil after excavation. We can only refer to the relevant research in other regions. When AGF is applied in a water-rich sand layer, improper control of the soil temperature can easily lead to water and sand gushing accidents, even collapsing tunnels. Therefore, in this paper, we describe in detail the frozen soil displacement and surface thaw settlement caused by the AGF-based excavation of a cross passage (analyzed through the finite-element simulation) and then measure and analyze the temperature development of the active freezing process of AGF-based construction. Our conclusions provide a foundation for the application of AGF-based construction in saturated sandy stratum layers in collapsible loess areas.

\section{Overview of Test Area}

The test setting is a cross passage project of the Xi'an metro-the distance between the centerlines of the left and right tunnels where the cross passage is located is $13.5 \mathrm{~m}$, the buried depth of the top is approximately $24.25 \mathrm{~m}$, the diameter of the tunnel is $6000 \mathrm{~mm}$, and the thickness of the tunnel segment is $300 \mathrm{~mm}$. The cross passage is a straight wall arch structure, with an excavation face height of $4.5 \mathrm{~m}$, a width of $3.3 \mathrm{~m}$, a top covering of soil of approximately $25 \mathrm{~m}$, and underground water buried at a depth of approximately $8 \mathrm{~m}$. Xi' an is located in the Guanzhong Basin (in the middle of the Yellow River Basin) comprising flat terrain. Its basic geomorphic types are river terraces and loess platforms, and the strata are composed of loess stratum and sand stratum. The river terraces and loess platforms in the project are characterized by a loess layer at the top with a sandy layer below. The stable depth below the surface of the groundwater table is approximately $4.10-12.00 \mathrm{~m}$, the elevation is approximately $360.32-368.22 \mathrm{~m}$ (the surface elevation is $372.32 \mathrm{~m}$ ), and the annual variation of the water level is approximately $2-3 \mathrm{~m}$. The cross passage is located in a medium sand layer, coarse sand layer, silty clay layer, and medium sand layer. The strata distribution, cross passage, and tunnel location are shown in Figure 1(b).

In the original design, rotary jet grouting pile reinforcement combined with drawdown was used to ensure the excavation safety of the cross passage. However, since the distance between the excavation area and railway culvert $\mathrm{A}$ was $50.3 \mathrm{~m}$, as shown in Figure 1(a), the surface settlement needed to be strictly controlled. To control the range of drawdown and prevent the groundwater loss of surrounding buildings during the process of drawdown, it is often necessary to take artificial recharge measures. This may cause the collapsible settlement of loess and affect the normal operation of the high-speed railway. Consequently, extracting groundwater at this location was prohibited. Research shows that for water-rich sand layers if the land surface does not have auxiliary drawdown conditions, the AGF method would 


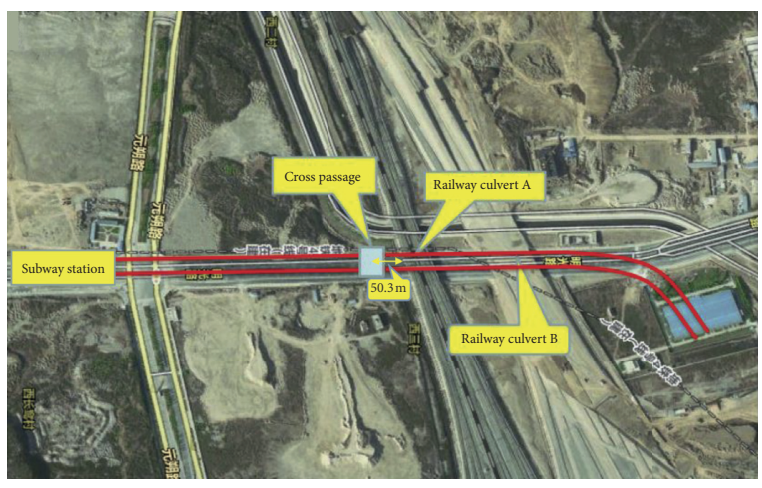

(a)
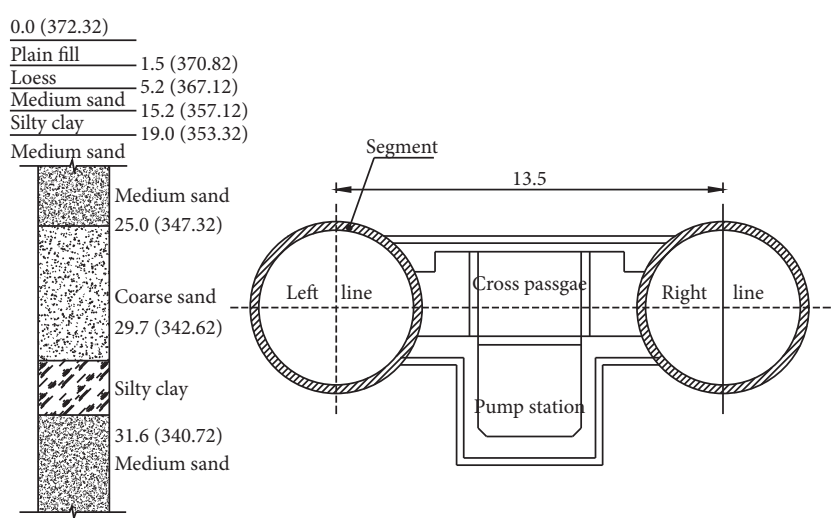

(b)

Figure 1: Metro section and cross passage: (a) plan view and (b) strata distribution and relative position of the cross passage and tunnel (unit: $\mathrm{m}$ ).

be the preferred construction method [18]. Therefore, a horizontal AGF method was designed to reinforce the ground, and the underground mining method was designed to ensure the safety of the cross passage construction and the continued operation of the high-speed railway.

\section{Test Scheme}

3.1. Test Implementation Scheme and Design Parameters. According to the standard [19], the geological and hydrologic conditions of the ground, the mechanical properties of the frozen soil, a number of other referenced projects, the following design indices, and construction parameters can be obtained. To ensure the excavation safety of the cross passage, the design indices of the frozen soil wall should meet the following requirements: the effective thickness of the frozen soil wall in the periphery should reach $2.6 \mathrm{~m}$, the uniaxial compressive strength should not be less than $4.0 \mathrm{MPa}$, the bending tensile strength should not be less than $1.8 \mathrm{MPa}$, and the shear strength should not be less than 1.6 MPa. To ensure that the frozen soil wall achieves the design index requirements, the average temperature at the interface between the frozen soil wall and the tunnel segment on the layout circle of the frozen holes around the excavation area must not be higher than $-5^{\circ} \mathrm{C}$, before the breaking of the tunnel portal. Further, the average temperature of the designed frozen soil wall in other sections must not be higher than $-10^{\circ} \mathrm{C}$. Consequently, the brine temperature during the active freezing period must be less than $-28^{\circ} \mathrm{C}$, with an active freezing time design of approximately 40-50 days (the actual active freezing time, 37 days, meets the design requirements).

3.2. Layout of the Freezing Hole and Temperature-Measuring Points. Low-temperature brine is used to cool the soil mass during construction. To ensure that the peripheral frozen soil wall meets the $2.6 \mathrm{~m}$ design requirement, the freezing holes are arranged in double-sided tunnels on the left and right lines: 51 freezing holes (hole numbers D1-D51) are arranged on the left line of the cross passage and 29 freezing holes (D52-D80) are arranged on the right line. D20-D23 and
D75-D76 of the middle left line are through holes. The freezing effect near a segment position is ensured by the freezing-row pipe and heat-preservation plate. The hole numbers of the freezing-row pipe are B1-B11. To monitor and release the frost-heaving pressure in the process of soil freezing in a timely way, four pressure relief holes are arranged in the closed area of the frozen soil wall, including two on the left and right lines of the tunnel (X1 and X2 and X3 and X4), respectively. The reason why freezing holes need not be arranged symmetrically on both sides is that the freezing effect can be basically guaranteed by the long and dense arrangement of the left freezing pipe, while the right freezing pipe plays a supplementary role in freezing, especially for the right soil mass. The pressure relief holes are arranged in the central area of the connecting channel because the frozen soil center often bears large frost-heaving pressure.

To ensure the safe excavation of the cross passage, 12 temperature-measuring holes are arranged on both sides of the left and right tunnel cross passage holes, and the excavation is carried out when the frozen soil wall reaches its design temperature and thickness. Four temperature-measuring holes $(\mathrm{C} 1-\mathrm{C} 4)$ are arranged on the tunnel left line where a freezing station is located, and eight temperature-measuring holes (C5-C12) are arranged on the tunnel right line. Among them, $\mathrm{C} 1, \mathrm{C} 2, \mathrm{C} 3, \mathrm{C} 4, \mathrm{C} 7, \mathrm{C} 9, \mathrm{C} 10, \mathrm{C} 11$, and $\mathrm{C} 12$ are located in the coarse sand layer, C5 is located in the silt layer, and C6 and C8 are located in the medium sand layer. The layout of the freezing, pressure relief, and temperature-measuring holes is shown in Figure 2.

As shown in Figure 3, there are three temperaturemeasuring points distributed along the hole depth, which are located at $0.5,1$, and $2 \mathrm{~m}$ radial depths. Each temperaturemeasuring point is numbered $\mathrm{C} x-1, \mathrm{C} x-2$, and $\mathrm{C} x-3$ $(x=1-12)$, from shallow to deep, respectively.

\section{Preanalysis of Construction Based on Numerical Simulation}

4.1. Basic Assumptions. In this project, the finite-element software ABAQUS was used for numerical analysis to verify 


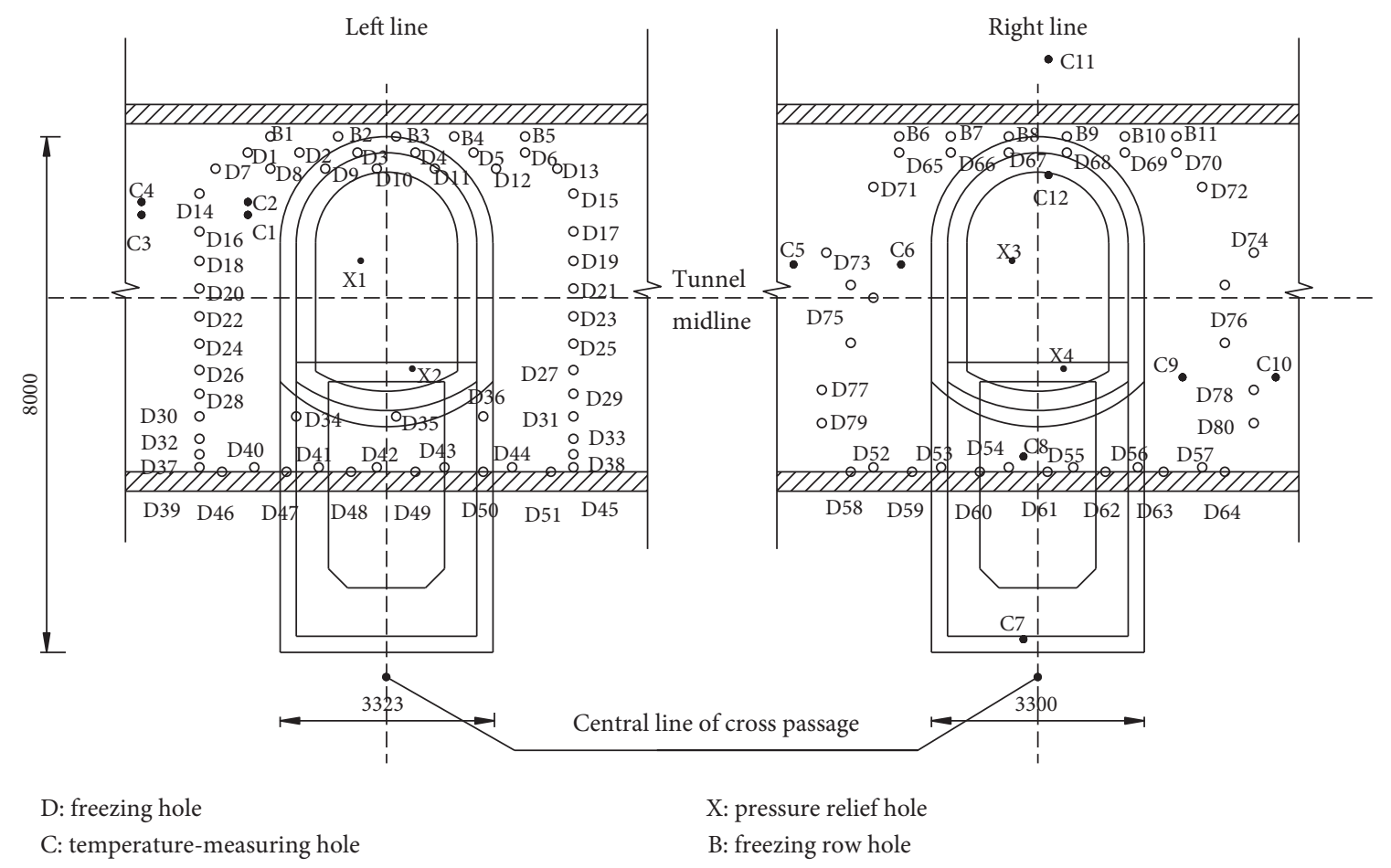

FIGURE 2: Layout of the freezing holes, temperature-measuring holes, pressure relief holes, and freezing row holes (unit: mm).

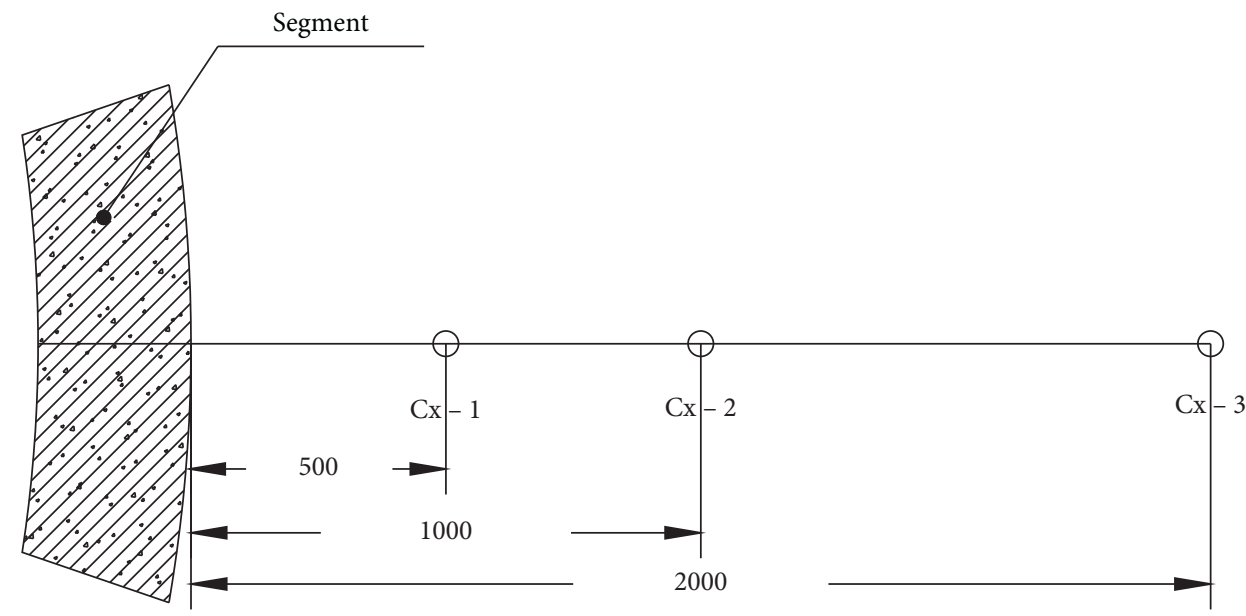

FIGURE 3: Layout of the temperature-measuring points (unit: $\mathrm{mm}$ ).

that under specific design parameters, the frozen soil wall could meet the requirements for safe excavation. The assumptions were as follows.

(1) The stratum is horizontal, and the thickness of each soil layer is uniform. The Mohr-Coulomb (M-C) model was adopted for the soil, and the elastic model was adopted for the tunnel segment. The smooth flow potential function [20] was adopted in the M-C model, as it avoided the phenomenon that the plastic flow direction was not unique at the sharp corner of the yield surface and improved the convergence speed of the calculation in ABAQUS. At the same time, the tunnel displacement calculated using the M-C model has many successful cases $[21,22]$.

(2) The tunnel segment was not the main research object, and it would not affect the calculation if it was regarded as an elastic body. Consequently, the elastic model was adopted.

(3) According to the design test parameters, the frozen soil wall was a $-10^{\circ} \mathrm{C}$ isothermal body, and the thickness of the frozen soil wall outside the tunnel portal was $2.6 \mathrm{~m}$.

(4) The soil in the frozen soil wall needed to be excavated at one time. In the actual excavation process of the 
cross passage, the measurements of the step-by-step excavation and support while excavating were adopted. Thus, the soil disturbance caused by the actual construction would have been less than that of the model, so the assumption was conservative.

(5) According to the symmetry of the cross passage, half of the soil mass and the cross passage were used to establish the model. The symmetry plane is $\mathrm{YOZ}$ in Figure 4. The calculation model is shown in Figures 4 and 5. Figure 4 shows the integral calculation model of the cross passage, and Figure 5 shows the relative position of the frozen soil wall and the tunnel lining after excavation.

\subsection{Model Parameters}

(1) The physical and mechanical parameters of each soil layer are listed in Table 1 . The data in Table 1 were measured using geotechnical tests in the laboratory after sampling through field surveys.

(2) In the AGF-based construction, the thermal conductivity and specific heat capacity of the soil were continuously changing in the freezing process, as these parameters of water and ice are significantly different and change with temperature.

(3) The frost-heaving coefficient is a key parameter of this model. Concerning the method of calculating the frost-heaving coefficient proposed by Wang et al. [23], the coefficient of the model soil at different temperatures can be obtained. The calculation principle is as follows:

$$
\alpha\left(T_{i}\right)=\frac{i_{\theta(i+1)}-i_{\theta i}}{i_{\theta}} \cdot \frac{\eta(1-\mu / 1+\mu)}{T_{i+1}-T_{i}},
$$

where $\alpha\left(T_{i}\right)$ is the frost-heaving coefficient of the soil at a certain temperature, $i_{\theta}$ is the relative ice content (the ratio of the ice mass to water mass in the soil mass) when the soil is completely frozen, $\mu$ is Poisson's ratio, $\eta$ is the frozen-heave factor. When the temperature of the frozen soil is $T_{i}$, the relative ice content is $i_{\theta i}$.

(4) In AGF-based construction, the soil has a different elastic modulus and Poisson's ratio under different negative temperatures, due to the effect of the soil moisture freezing into ice.

Table 2 lists the coefficient of frost heave, modulus of elasticity, Poisson's ratio, thermal conductivity, and specific heat capacity of the coarse sand layer with the greatest impact on the frozen soil wall under different temperatures. The frost-heaving coefficient is obtained using the calculation method mentioned in (1), and the specific heat, heat conductivity, elastic modulus, and Poisson's ratio are obtained through laboratory tests. The heat conductivity is measured using a thermal conductivity meter. The principle is based on Fourier's law:

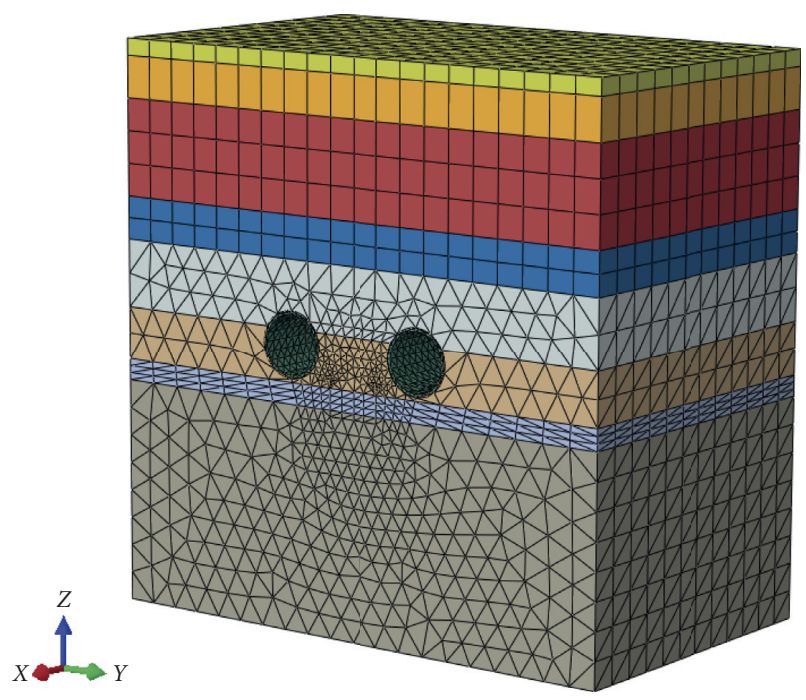

FIgURE 4: Integral finite-element model of the cross passage.

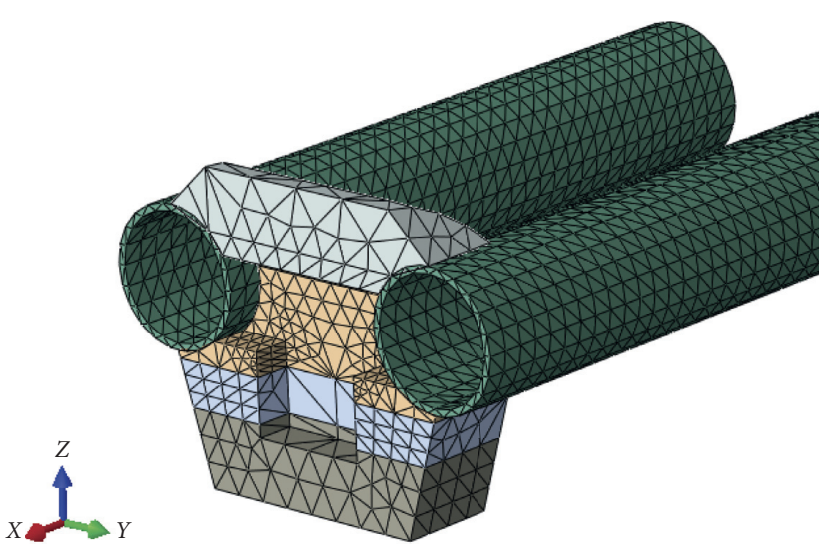

Figure 5: The cross passage and tunnel after the frozen soil wall excavation.

$$
q=\frac{Q}{A}=-k \frac{\mathrm{d} T}{\mathrm{~d} x}
$$

where $k$ is the heat conduction, $Q$ is heat, $A$ is the area, $(\mathrm{d} T / \mathrm{d} x)$ is the temperature gradient, and $q$ is the heat transfer intensity. The specific heat is measured by means of calorimetry, and the heat balance equation is as follows:

$$
C_{z}=\frac{\omega+C_{0} m}{M} \cdot \frac{t^{\prime}-t}{T-t^{\prime}}
$$

where $C_{z}, M$, and $T$ are the specific heat, mass, and temperature of the soil sample, respectively, $t, t \prime$, and $\omega$ are the initial temperature, final temperature, and heat capacity of the calorimeter, respectively, and $C_{0}$ and $m$ are the specific heat and mass of water, respectively.

\section{Results and Analysis}

5.1. Frost-Heaving Displacement of the Inner Wall of the Cross Passage. From a macroscopic point of view, the frost heave 
TABLE 1: The physical parameters of the soil layer.

\begin{tabular}{|c|c|c|c|c|c|}
\hline Soil layer number & Soil name & Cohesion $(\mathrm{kPa})$ & Angle of friction (degree) & Soil thickness (m) & Porosity \\
\hline 1 & Plain fill & 5 & 10 & 1.5 & - \\
\hline 2 & Loess & 29 & 24.5 & 3.7 & 0.47 \\
\hline 3 & Medium sand & 0 & 32 & 8.6 & 0.40 \\
\hline 4 & Silty clay & 32 & 17 & 3.8 & 0.41 \\
\hline 5 & Medium sand & 1 & 43 & 6.0 & 0.40 \\
\hline 6 & Coarse sand & 0 & 45 & 4.7 & 0.38 \\
\hline 7 & Silty clay & 32 & 17 & 1.9 & 0.41 \\
\hline 8 & Medium sand & 0 & 32 & 18.4 & 0.40 \\
\hline
\end{tabular}

TABLE 2: Related parameters of the coarse sand layer at different temperatures.

\begin{tabular}{|c|c|c|c|c|c|}
\hline Temperature $\left({ }^{\circ} \mathrm{C}\right)$ & Heat conduction $\left(\mathrm{W} /\left(\mathrm{m} \cdot{ }^{\circ} \mathrm{C}\right)\right)$ & $\begin{array}{l}\text { Specific heat } \\
\left(\mathrm{kJ} /\left(\mathrm{kg} \cdot{ }^{\circ} \mathrm{C}\right)\right)\end{array}$ & Frost-heaving coefficient $\left({ }^{\circ} \mathrm{C}^{-1}\right)$ & Elastic modulus (MPa) & Poisson's ratio \\
\hline 21 & 1.3 & 2.4 & 0 & 32 & 0.30 \\
\hline 0 & 1.7 & 1.8 & 0 & 34 & 0.29 \\
\hline-1 & 1.7 & 1.7 & -0.02125 & 50 & 0.28 \\
\hline-2 & 1.7 & 1.7 & -0.00575 & 50 & 0.28 \\
\hline-5 & 1.8 & 1.5 & -0.00400 & 98 & 0.25 \\
\hline-10 & 1.9 & 1.3 & -0.00082 & 170 & 0.23 \\
\hline
\end{tabular}

is caused by a decrease in the temperature and an increase in the pore water volume due to freezing-the lower the temperature, the larger the total degree of water freezing and the higher the frost heave rate. From a microcosmic point of view, the higher the frost heave rate, the more obvious the damage to the cementation between the particles in the soil becomes. The growth of ice crystals leads to the penetration of micropores in the soil and subsequently an increase in the pore volume [8]. Figure 6 shows the frost-heaving displacement nephogram in the $X-, Y$-, and $Z$-directions after the calculation of the frozen soil wall excavation.

As shown in Figure 6(a), the frost-heaving displacement in the $Y$-direction after soil excavation was significant on the sidewall of the frozen soil wall-in the pump station area, it is squeezed mainly into the pump station. The extreme value of the frost-heaving displacement in the $Y$-direction of the inner wall of the pump station was approximately -11.92 to $9.24 \mathrm{~cm}$. As shown in Figure 6(b), the frost-heaving displacement in the $Z$-direction after soil excavation was more significant at the top and bottom of the frozen soil wall. On the cross passage and the inner wall of the pump station, the displacement was primarily top-up and bottom-down. The extreme value was approximately -0.75 to $3.81 \mathrm{~cm}$. As shown in Figure 6(c), the frost-heaving displacement in the $X$-direction after soil excavation was relatively significant in the inner wall of the cross passage of the frozen soil wall, which was mainly manifested in the frost-heaving displacement of the soil toward the inner side of the cross passage. The maximum frost-heaving displacement in the $X$ direction was $11.35 \mathrm{~cm}$. The frozen soil on the inner wall of the cross passage and pump station moved inward in the $X$ and $Y$-directions, due to the excavation and unloading of the soil and the restrictions of the tunnel lining, but the inner wall still moved outward in the $Z$-direction. This is inconsistent with common sense and needs to be further analyzed.
During actual construction, although the soil exhibited frost heaving deformation, the cross passage excavation was conducted according to the design size in the frozen soil in which the frost heaving was produced. At this stage, the cross passage obtained from the excavation was not deformed. However, in the finite-element model, the elements to be excavated were set according to the design size before the frost heaving had produced any deformation (before excavation). The excavation of these units was conducted after the frost heaving, and by this stage, the cross passage had been deformed. Moreover, in actual construction, the displacement was observed in the cross passage with a standard shape after excavation, whereas in the finite-element model, the displacement obtained was the offset value between the model node after the frost heave and the initial model node-so the displacement range of the finite-element model and actual observations were different.

In view of the above, to ensure that the inner wall displacement of the cross passage is more in line with observed results, the initial incremental step of the displacement calculation analysis after the excavation of the soil should be used as the benchmark (in the finite-element model). The completion of all the incremental steps of the displacement calculation should be used as the culminating sign to measure the inner wall displacement increment of the cross passage in this section. Therefore, it is more reasonable to subtract the value of this point at the beginning of the excavation calculation from the aforementioned extreme value of the inner wall of the cross passage extracted from Figure 6. The frost-heaving displacement calculation of the inner wall of the cross passage is shown in Table 3.

Table 3 shows that the frozen soil on the inner wall in the $Y$ - and $X$-directions still displaced toward the inner side of the cross passage and the pump station. The reasonable extreme values were approximately -13.83 to $10.93 \mathrm{~cm}$ and 


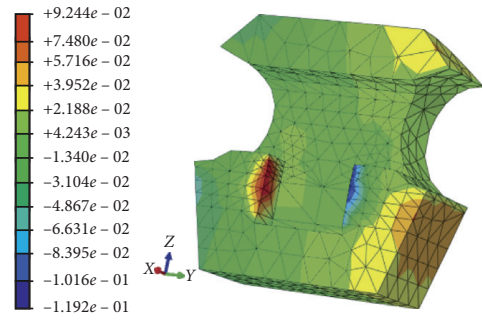

(a)

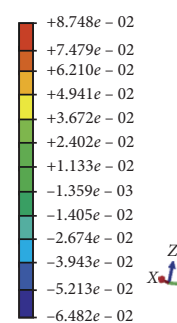

$-6.482 e-02$

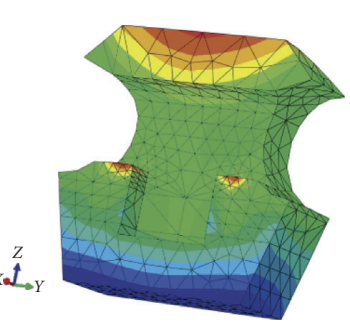

(b)

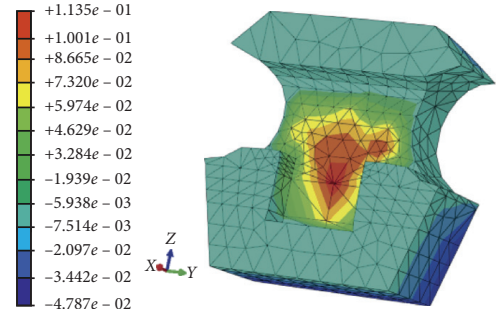

(c)

Figure 6: Nephograms of the frost-heaving displacement after the cross passage excavation displacement calculation (unit: $\mathrm{m}$ ): (a) $Y$ direction, (b) Z-direction, and (c) $X$-direction.

TABle 3: Calculation of the frost-heaving displacement of the inner wall of the cross passage.

\begin{tabular}{lcccc}
\hline $\begin{array}{l}\text { Displacement } \\
\text { direction }\end{array}$ & $\begin{array}{c}\text { Location of } \\
\text { inner wall }\end{array}$ & $\begin{array}{c}\text { Extreme value of frost heave } \\
\text { after excavation } \\
\text { calculation }(\mathrm{cm})\end{array}$ & $\begin{array}{c}\text { Extreme value of frost heave at } \\
\text { the beginning of excavation } \\
\text { calculation }(\mathrm{cm}) \\
B\end{array}$ & $\begin{array}{c}\text { Reasonable extreme value of } \\
\text { frost-heaving displacement after } \\
\text { excavation }(\mathrm{cm}) \\
A-B\end{array}$ \\
\hline \multirow{2}{*}{$Y$-direction } & Left & 9.24 & -1.69 & 1.91 \\
\hline \multirow{2}{*}{$Z$-direction } & Right & -11.92 & 6.46 & -13.83 \\
& Bop & 3.81 & -4.61 & -2.65 \\
\hline$X$-direction & Middle & -0.75 & -1.40 & 3.86 \\
\hline
\end{tabular}

$12.75 \mathrm{~cm}$, respectively, which were not much different from result A shown in Table 3. The restraint effect of the tunnel lining effectively reduces the frost-heaving displacement of the soil before excavation. In the $Z$-direction, the displacement of the frozen soil on the inner wall of the cross passage was opposite to that of result A (Table 3). The top and bottom displacements of the frozen soil on the inner wall of the cross passage were downward and upward, respectively, and the reasonable extreme values were approximately -2.65 to $3.86 \mathrm{~cm}$. At this stage, the displacement direction obtained was consistent with the actual observation and could be used to guide the project.

5.2. Surface Thaw Settlement. After freezing, thawing settlement occurs in the process of increasing soil temperature. The main causes of thawing settlement are the decreasing volume of water formed by ice melting, and the destruction of the soil microstructure by ice crystals during freezing, which weakens the structural properties of the soil. The thawing settlement of the soil mass has a great impact on the surface settlement. For railway culvert A, which is $50.3 \mathrm{~m}$ away from the cross passage, the surface settlement caused by the subway construction must be less than $5 \mathrm{~mm}$. Since the shield tunneling before the construction of the cross passage caused the settlement of railway culvert $A$ to be $1.8 \mathrm{~mm}$, the settlement caused by the construction of the cross passage must be controlled to within $3.2 \mathrm{~mm}$. Figure 7 shows the distribution curve of the final thaw settlement of the ground surface under the construction of the AGF-based cross passage obtained using finite-element simulation. Figure 7 (a) shows the distribution of the surface settlement along the centerline ( $Y$-direction) of the cross passage, and
Figure $7(\mathrm{~b})$ shows the distribution along the centerline $(X-$ direction) of the two shield tunnels. The distribution curve of the surface settlement along the $X$-direction (shown in Figure $7(\mathrm{c})$ ) can be obtained using symmetry.

Figure 7 shows that the numerical simulation result of the maximum cumulative surface settlement of the construction was approximately $14 \mathrm{~mm}$. The closer the centerline of the cross passage, the greater the final thawing settlement of the surface, which was mainly related to the amount of frozen soil and the excavation and unloading of the cross passage. The red curves in Figures 7(a) and 7(c) are the settlement trough curves fitted using the Peck formula. The surface settlement trough curve caused by thawing settlement is regarded as a quasinormal distribution. Peck [24] proposed that the surface settlement trough of the tunnel is a quasinormal distribution, and the Peck formula is as follows:

$$
S(x)=S_{\max } \exp \left(-\frac{x^{2}}{2 i^{2}}\right),
$$

where $S(x)$ is the surface settlement value at $x$ from the tunnel centerline, $S_{\max }$ is the maximum surface settlement value at the tunnel centerline, $x$ is the horizontal distance from the tunnel centerline, and $i$ is the width coefficient of the surface settlement trough-that is, the horizontal distance from the inflection point of the settlement trough curve to the tunnel centerline.

$i$ of the fitting curve in Figure 7(c) was taken to be $8.51 \mathrm{~m}$, and the numerical simulation results were similar to the fitting curve itself. According to the algorithm proposed by Peck, the influence range of the settlement trough is $5 i$-that is, the surface settlement at $2.5 i(21.28 \mathrm{~m})$ from the tunnel 


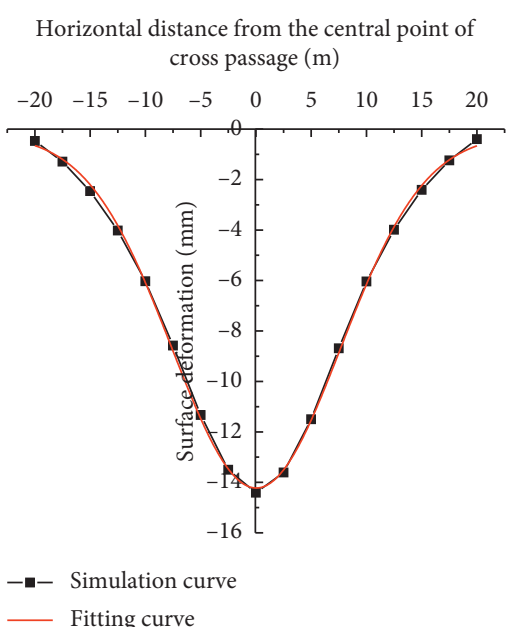

(a)

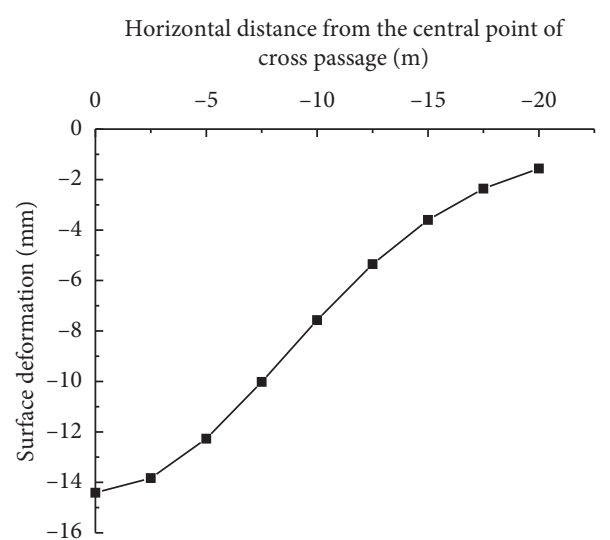

(b) Horizontal distance from the central point of
cross passage $(\mathrm{m})$

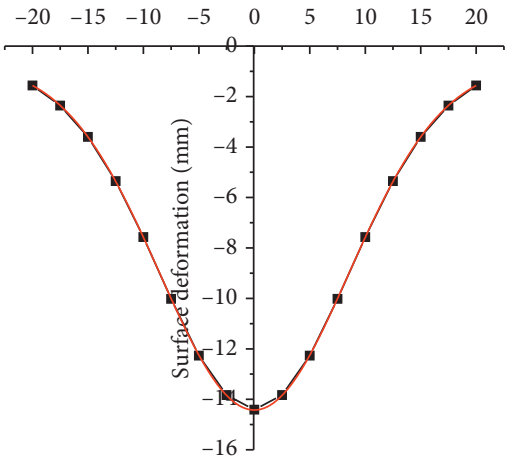

-- Simulation curve

(c)

Figure 7: Distribution of the final surface thawing settlement: (a) along the centerline of the cross passage ( $Y$-direction), (b) along the centerline of the two shield tunnels (X-direction), and (c) along the centerline of the two shield tunnels after symmetry (X-direction).

centerline is $0 \mathrm{~mm}$, and the calculated value of $S(21.28)=-0.63 \mathrm{~mm}$. Some scholars think that the width of the surface settlement trough should be $6 i$-that is, the surface settlement at $3 i(25.53 \mathrm{~m})$ from the axis is $0 \mathrm{~mm}$ [25]. At this stage, $S(25.53)=-0.16 \mathrm{~mm}$. It is more appropriate to take the latter $(25.53 \mathrm{~m})$ as the influence width of the settlement trough. Therefore, since the thaw settlement had little impact on the surface $25.53 \mathrm{~m}$ away from the centerline of the cross passage along the shield tunnel direction, it had no adverse impact on railway culvert A, $50.3 \mathrm{~m}$ away from the cross passage.

The above numerical simulation results demonstrated that the scheme and design parameters of the AGF test for the cross passage were both effective and feasible and that the impact of construction on the cross passage itself and the surface was within an acceptable range. Consequently, the AGF test could be conducted.

\section{Field Test Results and Analysis}

In the field test, drilling officially started on August 9, 2017, and all drilling work was completed by August 31, 2017. On September 1, 2017, freezing started, with an active freezing period of 37 days. On October 8 of the same year, the tunnel portal was broken, and the cross passage was excavated. The layout of the site freezing station and the installation of the freezing pipe are shown in Figure 8.

6.1. Freezing Development Rate. Figure 9 shows the freezing development rate of each measuring point, which is calculated as follows:

$$
v=\frac{l}{t}
$$

where $v$ is the freezing development rate of the measuring point, $l$ is the distance from the measuring point to the nearest freezing hole, and $t$ is the number of days before the temperature of the measuring point reaches zero after the project site starts to freeze.

Figure 10 shows the distance from each measuring point to the nearest freezing hole. Generally, the closer the measuring point is to the nearest freezing hole, the faster the freezing development rate should be. Based on a comparison between Figures 9 and 10, some measuring points conform to the above laws, such as C1-1, C3-1, C7-1, C10-1, and C111. However, some of the measuring points do not. For example, the distance from measuring point $\mathrm{C} 4$ to the nearest freezing hole was the smallest, but its freezing development rate was slower than that of measuring point $\mathrm{C} 1$. The reason being that measuring point $\mathrm{C} 1$ was located on the inner side of the frozen soil wall while measuring point $\mathrm{C} 4$ was located on the outer side of the frozen soil wall. At the same time, measuring point $\mathrm{C} 1$ was surrounded by more frozen pipes, so it was affected by more frozen pipes at the same time. This meant that the heat transfer efficiency of the soil inside the frozen soil wall surrounded by frozen pipes was higher than that of the soil outside the frozen soil wall. This conclusion can also be proved by the fact that the freezing development rates of C6, C8, C9, and C12 on the inner side of the freezing wall were higher than those of $\mathrm{C} 5$, $\mathrm{C} 7, \mathrm{C} 10$, and $\mathrm{C} 11$ on the outer side. In summary, in determining the development rate of the freezing wall, one needs to consider the internal and external positions of the frozen soil wall and the cooperative actions of the frozen pipes. This means that as the soil in the inner side of the frozen soil wall receives more cooperative heat conduction from the freezing pipes, the inward development rate of the frozen wall is faster than its outward development rate.

6.2. Regularity of Salt Water Temperature Change. The project used low-temperature brine to cool the soil mass. The temperature-measuring data of the inlet and outlet in the active freezing period are shown in Figure 11. According to our analysis of the measuring data, the temperature change 


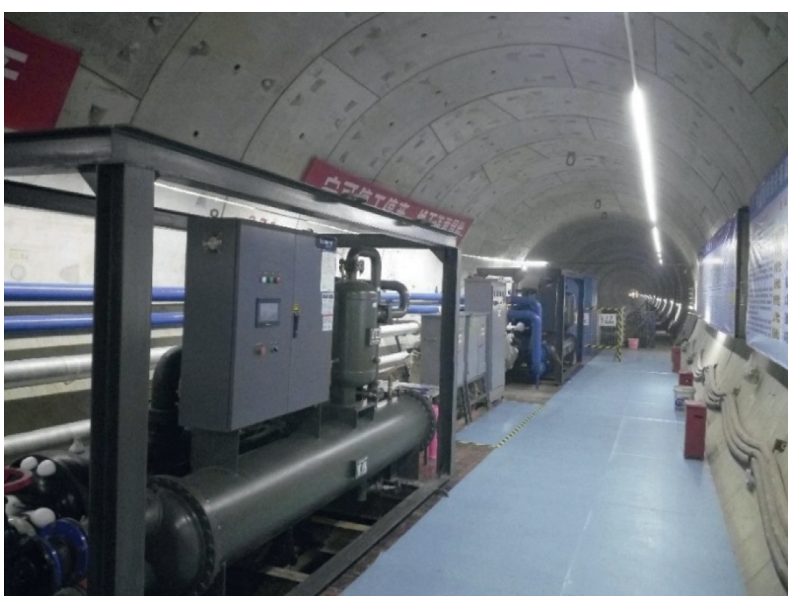

(a)

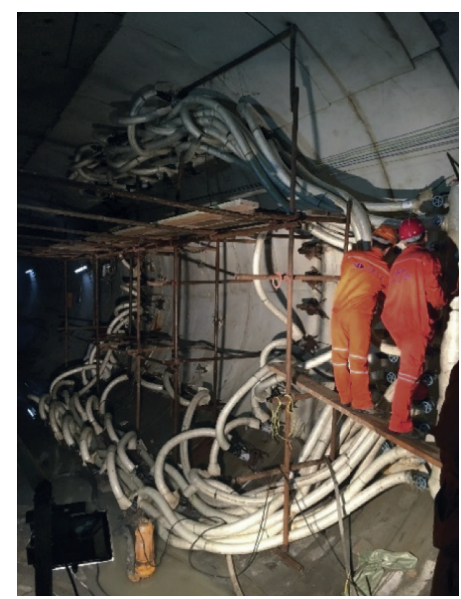

(b)

Figure 8: (a) Layout of the freezing station in the tunnel and (b) the installation of the freezing pipe.

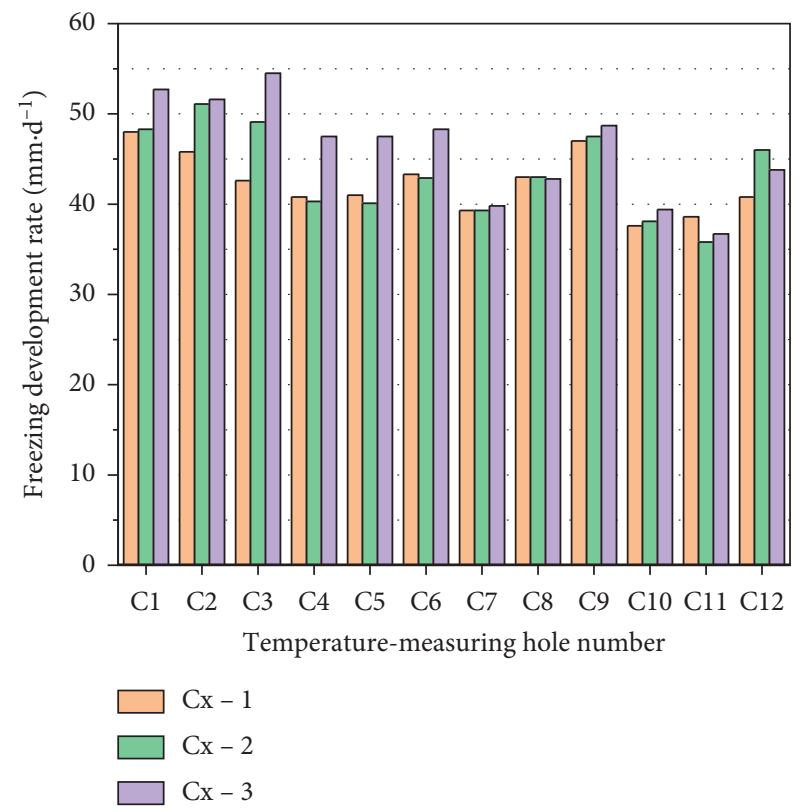

FIGURE 9: Freezing development rate of each measuring point.

of the brine inlet and outlet in the active freezing period could be divided into three stages: the first stage lasted for approximately seven days, as the temperature of the brine dropped rapidly. At this stage, the average cooling rate is $1.69^{\circ} \mathrm{C} / \mathrm{d}$, and the temperature difference between the inlet and outlet was quite pronounced. The temperature difference reached $2.2^{\circ} \mathrm{C}$ during the first and second days of freezing, after which the temperature difference between the inlet and outlet gradually decreased. The second stage lasted for approximately 18 days. From the eighth day of freezing, the temperature of the brine was maintained at approximately -24.7 to $-29.7^{\circ} \mathrm{C}$. During this stage, the temperature difference between the inlet and outlet removal was stable at approximately $1.1^{\circ} \mathrm{C}$, which indicated that the decreasing soil

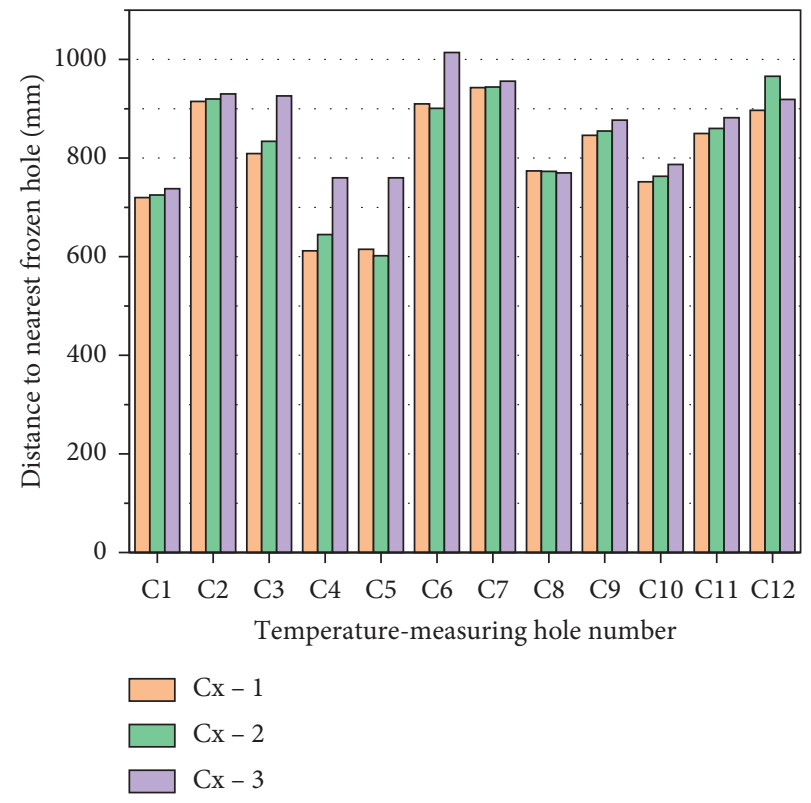

FIGURE 10: Distance from each measuring point to the nearest freezing hole.

temperature and the developing effect of the freezing process were better. During the third stage, the temperature of the brine was maintained at approximately -30 to $-31.1^{\circ} \mathrm{C}$, and the temperature difference between the inlet and outlet was kept within $0.9^{\circ} \mathrm{C}$, which indicated that the heat exchange of the soil was further reduced, and the development of the frozen soil wall was good.

6.3. Regularity of Soil Temperature Change. As shown in Figure 12, to obtain the temperature development and distribution rule of the frozen soil wall during the active freezing period, the $\mathrm{C} 9-\mathrm{C} 12$ measuring holes on the same interface of the frozen soil wall were used as examples, to 


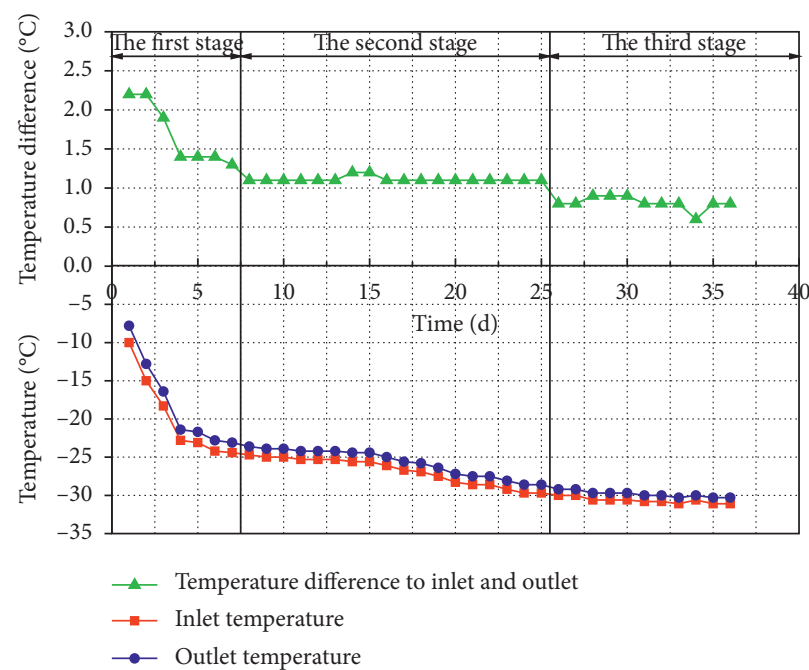

Figure 11: Temperature and temperature difference curves of the brine inlet and outlet.

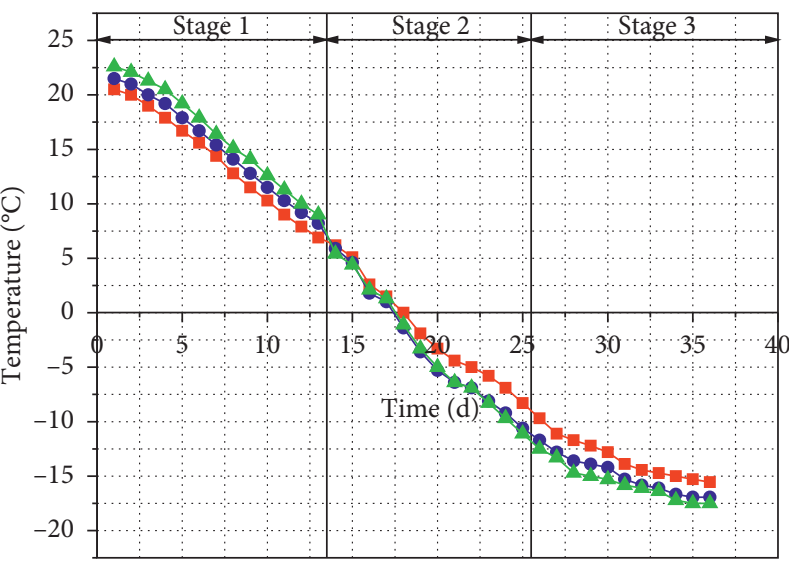

$\rightarrow \mathrm{C} 9-1$

- $\mathrm{C} 9-2$

$-\mathrm{C} 9-3$

(a)

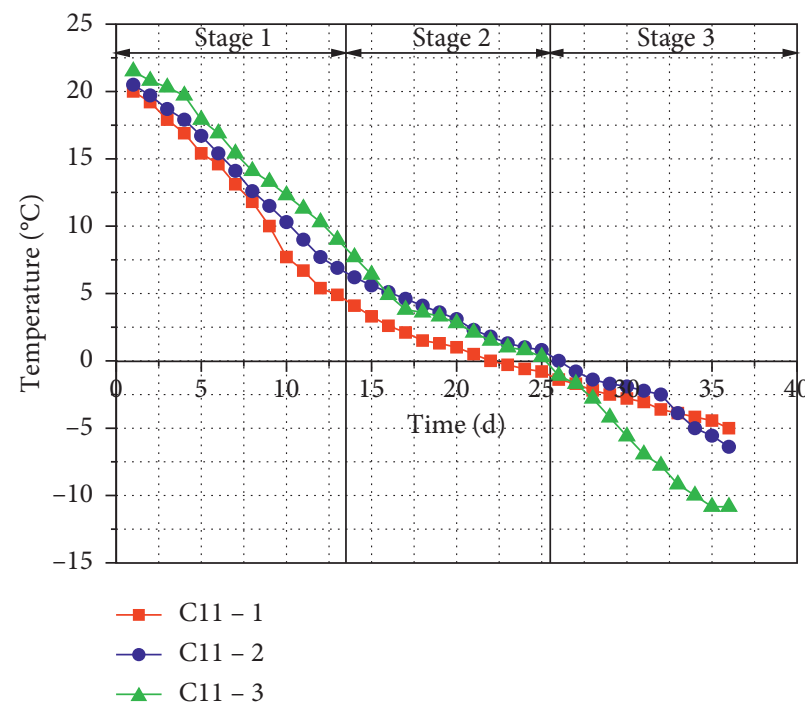

(c)

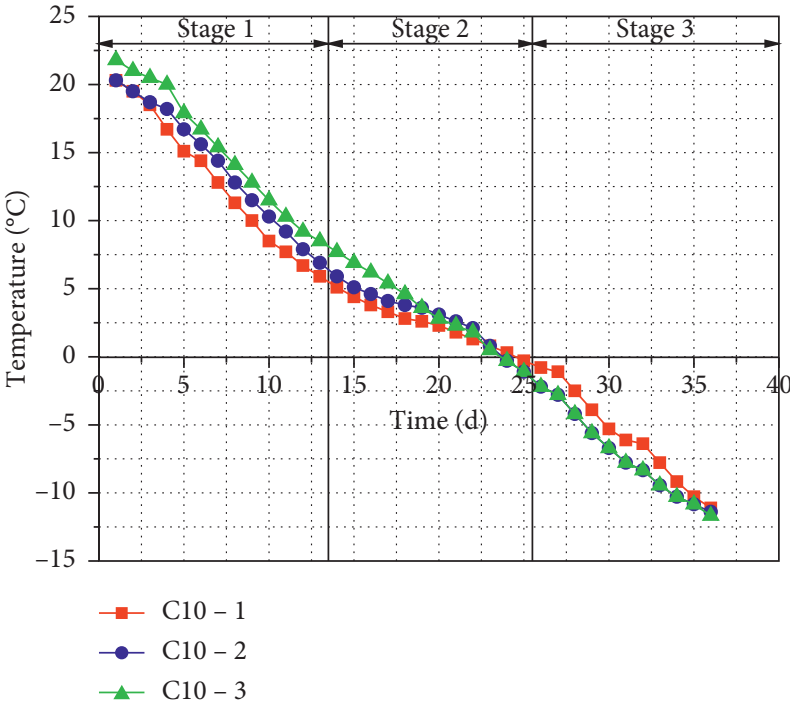

(b)

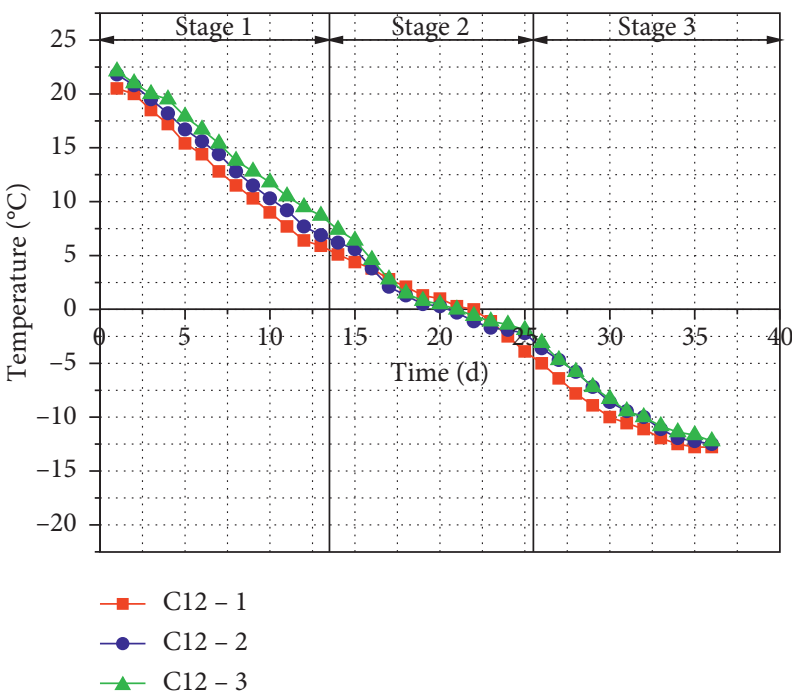

(d)

FIGURE 12: Correlation between the temperature of measuring points and freezing days: (a) C9, (b) C10, (c) C11, and (d) C12. 
study the correlation of the temperature of the measuring point and the freezing days. The numbering of the measuring points in Figure 12 was $\mathrm{Cx}-1-\mathrm{Cx}-3$, from the radial direction of the segment to the internal soil.

The temperature trends for each measuring point in the active freezing period with freezing days were approximately the same. The process can be divided into three stages, based on its change rules. Using C9 as an example, in active freezing stage 1, the temperature of the soil layer was high, and the temperature difference between the brine and soil layer was large. Thus, the temperature of the temperaturemeasuring hole decreased rapidly. With the decreasing temperature, the temperature difference between the soil layer and brine gradually decreased, and so the cooling rate itself gradually decreased. This lasted for about 13 days, at an average cooling rate of $1.05^{\circ} \mathrm{C} / \mathrm{d}$. In active freezing stage 2 , which lasted approximately 12 days, the average cooling rate was $1.19^{\circ} \mathrm{C} / \mathrm{d}$. During this stage, the temperature of the soil mass where $\mathrm{C} 9$ was located was close to $0^{\circ} \mathrm{C}$, initially. Affected by the latent heat of water, the cooling rate of the soil mass slowed down, and the water in the soil around the freezing pipe gradually froze, to form frozen soil. At this stage, as the latent heat of the fusion process was completed, the frozen soil developed gradually, accelerating the cooling rate again, to form a frozen soil wall, resulting in the development rate and the thickness of the freezing wall increasing gradually. In active freezing stage 3 , the soil temperature gradually reached the design temperature, tending toward stability. The temperature difference between the brine in the inlet and outlet was kept within $0.9^{\circ} \mathrm{C}$, the frozen soil wall almost reached its design thickness, the heat exchange was essentially balanced, and the soil temperature declined gradually. The average cooling rate during this stage was $0.45^{\circ} \mathrm{C} / \mathrm{d}$.

Figure 12 shows that the temperature change amplitude of $\mathrm{Cx}-1$ was smaller than that of $\mathrm{Cx}-3$. This means that the soil with a small longitudinal cross passage depth had a smaller cooling change gradient than that with large longitudinal depth. The analysis is as follows. At the start of freezing, the longitudinal shallow position of the cross passage began to exchange heat with the brine; at this stage, the temperature of the shallow position was lower than that of the deeper position. After the formation of the frozen soil wall, the segment dissipated heat by air convection, so the soil near the segment had a certain heat conduction loss due to the longitudinal shallow position of the cross passage being close to the segment, resulting in a temperature rise. The closer this was to the segment, the slower the temperature decrease of the measuring point. At this stage, the longitudinal shallow position of the cross passage had a higher temperature than the longitudinal deep position of the cross passage.

6.4. Regularity of the Pressure Relief Hole Pressure Variation. In the construction process using the AGF method, the volume of water condensed into ice increases. This is called "frost heave," and it produces a frost heave force. To monitor the frost heave force in the frozen soil wall and release excessive frost heave force, four pressure relief pipes are arranged in the closed area of the frozen soil wall-two on the left and two on the right lines (X1 and X2 and X3 and $\mathrm{X} 4)$, respectively. The front end of the pressure relief pipe was opened, and several holes of quincunx distribution were drilled into the pipe wall buried in the soil, to ensure the effective transmission of pressure in the frozen soil wall. The pressure gauge installed in the pressure relief hole (Figure 13) could visually monitor the changing pressure in the frozen soil wall and could be used to judge the formation of the frozen soil wall over time. The working principle of the pressure relief hole (design to release frost-heaving pressure) is that when the pressure at the pressure gauge rises, the pressure relief hole valve is opened, and the compressed soil enters the pressure relief pipe through the pipe wall hole and then discharges from the pressure relief hole.

The pressure change of the pressure relief hole is shown in Figure 14. Since there was no hydraulic connection between the pressure relief hole and the periphery of the cross passage freezing circle, the pressure buildup was caused by the closure compression of the frozen soil wall. Therefore, the soil pressure growth can be used as the basis for the closure of the frozen soil wall. The specific analysis is as follows. The original formation pressure of the four relief holes on the left and right lines was $\mathrm{X} 1=0.12 \mathrm{MPa}$, $\mathrm{X} 2=0.10 \mathrm{MPa}, \mathrm{X} 3=0.11 \mathrm{MPa}$, and $\mathrm{X} 4=0.10 \mathrm{MPa}$, respectively. In active freezing stage 1 , the pressure of the pressure relief hole was maintained at approximately $0.11 \mathrm{MPa}$, and the soil was not frozen at this stage. Therefore, the change of the temperature field did not cause any obvious increase in the soil pressure. Active freezing stage 2 lasted for approximately 12 days, and the frozen soil wall was closed on the $8^{\text {th }}$ day of this stage. This caused the soil frost-heaving pressure to increase rapidly, along with the pressure of the pressure relief hole. In active freezing stage 3, the frostheaving pressure reached a maximum value $(0.42 \mathrm{MPa})$ in the first five days of this stage, which indicated that the frozen soil wall had a large area of closure; subsequently, under the action of the pressure relief hole, the frost-heaving pressure dropped (the minimum was close to $0 \mathrm{MPa}$ ), and the pressure relief hole valve was closed; next, due to the development of the freezing soil wall, the frost-heaving pressure reached a peak again on the $34^{\text {th }}$ day, after which, under the action of the pressure relief hole, the $35^{\text {th }}$ day pressure dropped to $0 \mathrm{MPa}$. Meanwhile, no frost-heaving pressure was generated in the vicinity of the pressure relief hole, which indicated that the frozen soil wall was no longer developing at this stage. Therefore, the maximum thickness of the frozen soil wall was reached by the $34^{\text {th }}$ day. After the $38^{\text {th }}$ day, it entered a maintenance freezing stage.

\subsection{Frozen Soil Wall Thickness and Average Temperature.} Figure 9 shows that the slowest development rate of the frozen soil in the cross passage was $35.8 \mathrm{~mm} / \mathrm{d}$, so the development radius of the frozen soil could be calculated as $r=35.8 \times 37 d=1324.6 \mathrm{~mm}$. As such, the predicted section of the frozen soil wall was designed according to this radius, as shown in Figure 15. The drawing dimensions reveal that the 


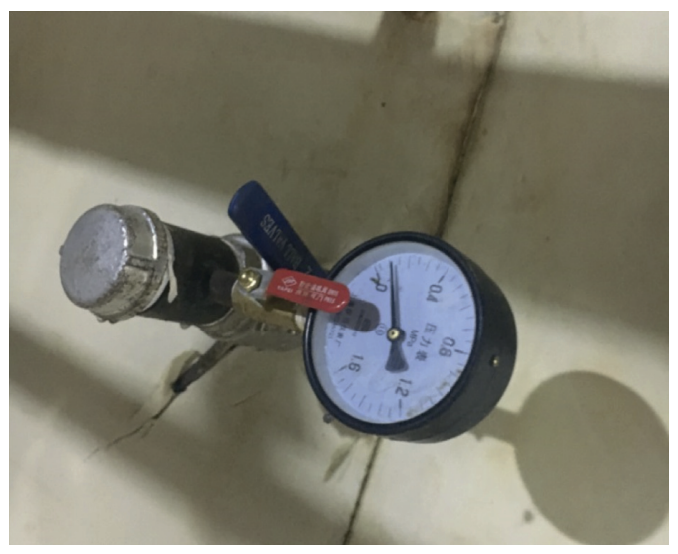

FIgURE 13: Pressure gauge in the pressure relief hole.

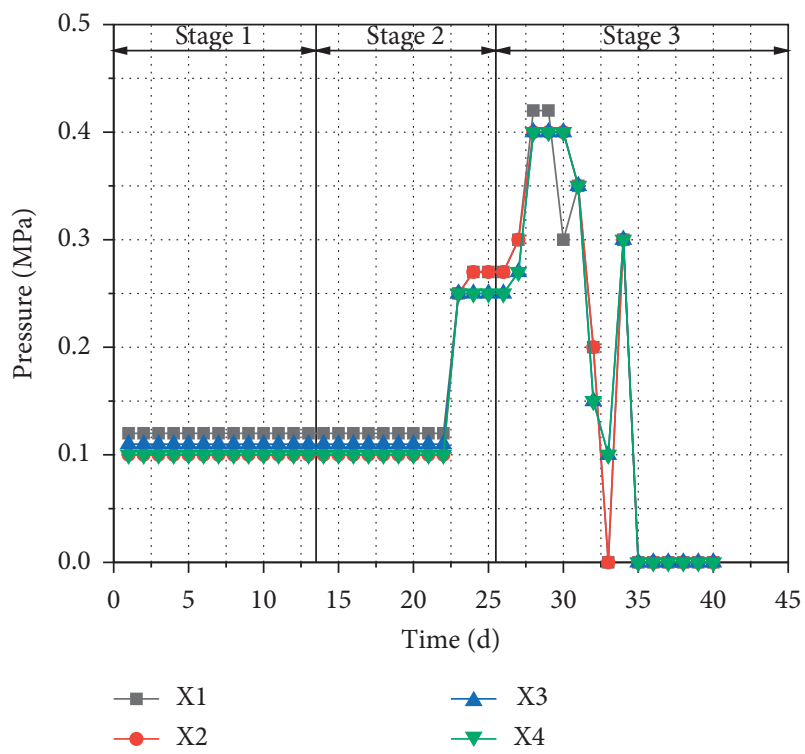

Figure 14: Correlation between the pressure of the pressure relief hole and freezing days.

minimum thickness of the cross passage frozen soil wall was $2.625 \mathrm{~m}$, which was larger than the design requirement of $2.6 \mathrm{~m}$. Therefore, the excavation could be done. After the tunnel portal was broken, the actual frozen diameter was found to be approximately $70 \mathrm{~cm}$ larger than the design diameter. Therefore, the thickness of the frozen soil wall calculated using the slowest development rate of the frozen soil was more conservative, and the calculated active freezing period was longer.

The average temperature of the frozen soil wall is calculated according to the "ice forming formula" [26]:

$$
\begin{aligned}
t= & t_{b}\left(1.135-0.352 \sqrt{l}-0.875 \frac{1}{\sqrt[3]{H}}+0.266 \sqrt{\frac{l}{H}}\right) \\
& -0.466+0.25 t_{B}=-12.609^{\circ} \mathrm{C},
\end{aligned}
$$

where $t$ is the average temperature of the frozen soil wall, $t_{\mathrm{b}}$ is the brine temperature of $-30.6^{\circ} \mathrm{C}, \mathrm{H}$ is the thickness of the frozen soil wall of $2.625 \mathrm{~m}, l$ is the maximum hole spacing of

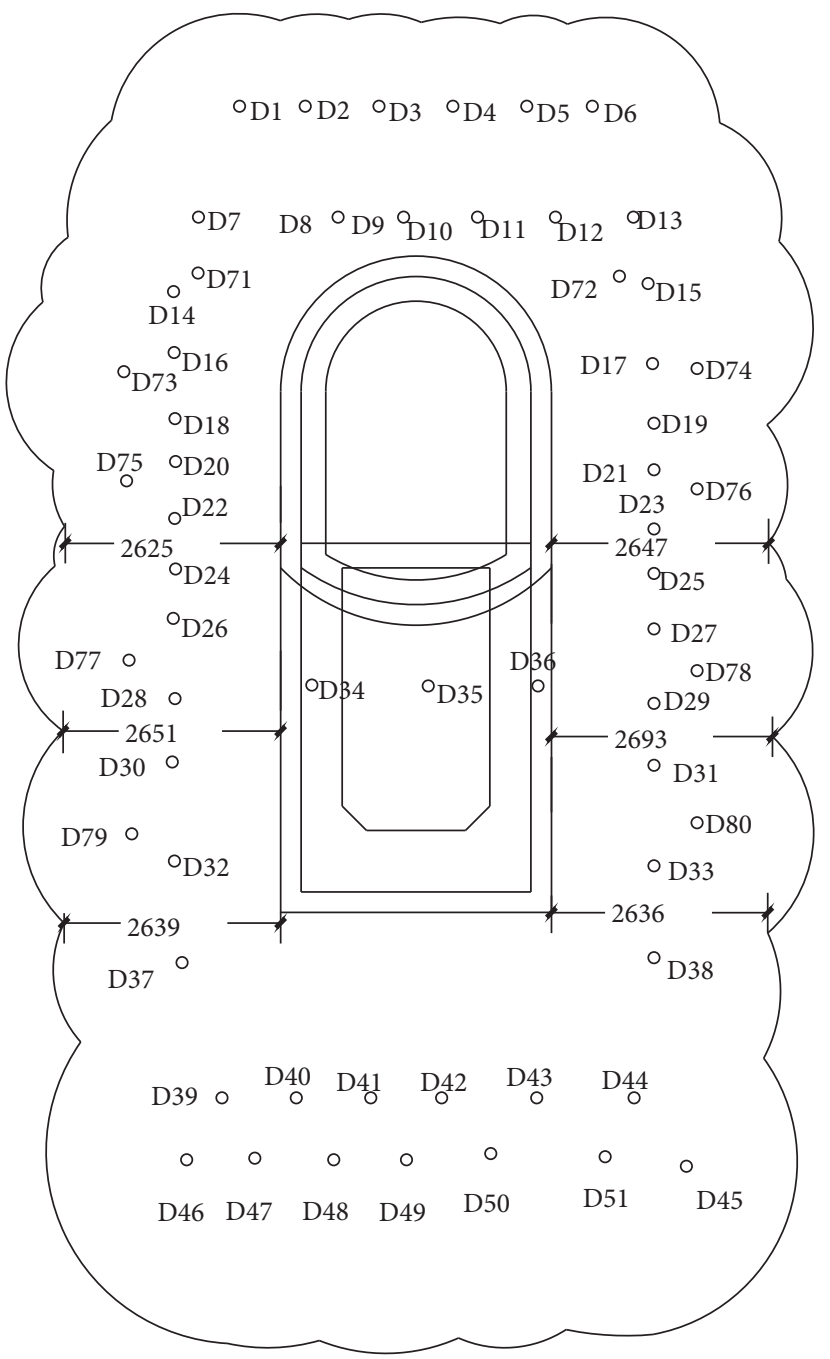

FIGURE 15: Forecast section of the frozen soil wall (unit: $\mathrm{mm}$ ).

$1.10 \mathrm{~m}$, and $t_{\mathrm{B}}$ is the maximum temperature of the temperature-measuring hole in the inside of the frozen soil wall, which is $-11.4^{\circ} \mathrm{C}$.

According to equation (3), the average temperature of the frozen soil wall of the cross passage was $-12.6^{\circ} \mathrm{C}$, which was lower than the design value of $-10^{\circ} \mathrm{C}$, meeting the design requirements and ensuring that the soil freezing effect was good after excavation.

6.6. Surface Settlement and Compensation Grouting. The measured maximum cumulative surface settlement was less than $6 \mathrm{~mm}$, which was different from the simulation results mentioned above. The reason for this difference is not only due to the basic assumptions of the model and the soil constitutive model but also because the model fails to effectively simulate the compensation grouting. To prevent excessive surface settlement during the natural thawing period, compensation grouting should be carried out in the field test within three to seven days of the freezing stopping. The conclusion of compensation grouting is based on the stability of the surface deformation. When the surface 
settlement was kept within $0.3 \mathrm{~mm}$ every half month, for a continuous month, the compensation grouting could end.

Compensation grouting is a process of soil reinforcement, which can be roughly divided into three stages. In the first stage, the water in the soil is replaced by a slurry, and the void in the fill is filled. The quantity of grouting depends on its porosity. In the second stage, the slurry compacts the soil and forms a cylindrical slurry, which results in the radial elastic-plastic deformation of the soil. In the third stage, with increasing grouting pressure, the slurry causes the soil to split in the horizontal direction, forming a horizontal or reticular slurry vein skeleton, which imposes a large upward lifting force on the soil. The filling and replacement effect of the compensation grouting on the soil body reinforces the soil, which is the same effect as that of grouting in general. Therefore, the long-term effect of compensation grouting improves the bearing capacity of the local soil.

\section{Discussion}

The numerical model in this paper has some limitations. The numerical simulation is used as the construction preanalysis to obtain the displacement results of the inner wall and surface thawing settlement of the cross passage. However, due to the limitation of the field conditions, there are no detailed measured data as a comparative analysis. Therefore, the displacement results obtained by simulation are mainly used for qualitative analysis.

In the process of soil cooling, the closer the soil was to the tunnel segment, the slower was the cooling rate because the segment dissipated heat by air convection. This reminds the construction personnel that the influence of external heat sources should be reduced as much as possible in AGF-based construction, lest they hinder the cooling process.

The calculation of the average temperature of the frozen soil wall using equation (6) is not accurate, as the calculation of the average temperature is performed before excavation, and the thickness of the frozen soil wall is a result of the calculation rather than the measurement.

In calculating the thickness of the frozen soil wall, the calculated value is less than the actual value, which is probably related to the water migration law of frozen soil-that is, during the freezing and thawing process of the soil, the water migrates to the frozen soil $[27,28]$ so that the frozen volume is larger than expected. However, the amount of influence this has on the frozen soil wall itself is worthy of further study.

Although the stability of the surface settlement means the end of the construction, the long-term influence of AGFbased construction on the ground and the structure is also worthy of attention. Firstly, through the freeze-thaw cycle tests conducted by several scholars $[6,7]$, after the 1 to 2 freeze-thaw cycles, the structure of loess will change significantly and the cohesion will decrease rapidly. Therefore, compensation grouting is a very important postconstruction measure. Moreover, the water migration caused by freezing and thawing makes the water near the cross passage accumulate over a short period, the impact on the subway tunnel and the cross passage of which is worth long-term monitoring. Finally, although compensation grouting can strengthen the soil, it also brings pollution to the underground environment [29], which may have little impact on the structure in the short term, but it will have a long-term impact on the microbial and hydrological environment. It would be worthwhile paying attention to whether compensation grouting will bring long-term adverse effects to the structure-this needs to be studied from an engineering and environmental perspective.

\section{Conclusion}

(i) In saturated sandy stratum in collapsible loess areas, since the unit soil on the inner side of the frozen soil wall receives more cooperative heat conduction from the freezing pipes over the same period, the inward development rate of the frozen wall is faster than its outward development rate.

(ii) The gradient of the soil cooling curve is positively related to the longitudinal depth of the cross passage. At the start of the freezing period, the temperature in the deeper longitudinal position of the cross passage was higher than that in the shallower position; at the end of the active freezing period, the temperature in the deeper longitudinal position was lower than that in the shallower position.

(iii) The thickness of the frozen soil wall calculated using the slowest development rate of the frozen soil was conservative, with a value of $2.625 \mathrm{~m}$, while the actual thickness was $3.3 \mathrm{~m}$.

(iv) A pressure relief hole was beneficial to the release of the frost-heaving force and the control of the frost-heaving displacement. The pressure increase of the pressure relief hole could be used as the basis for the identification of the closure of a frozen soil wall.

(v) After the excavation of the frozen soil wall, the frozen soil in the inner wall of the cross passage moved toward its inner space.

\section{Data Availability}

The data used to support the findings of this study are available from the first author upon request.

\section{Conflicts of Interest}

The authors declare that there are no conflicts of interest regarding the publication of this paper.

\section{Acknowledgments}

This study was supported by the Key Research and Development Project of Shaanxi Province (grant no. 2020SF-373) and the Special Research Project of Shaanxi Provincial Education Department (grant no. 19JK0381). 


\section{References}

[1] H. Hab and P. Schafers, "Application of ground freezing for under-ground construction in soft ground," in Proceedings of the Geotechnical Aspects of Underground Construction in Soft Ground, pp. 405-412, Taylor \& Francis, London, UK, 2006.

[2] J. Hu, Y. Liu, H. Wei, K. Yao, and W. Wang, "Finite-element analysis of heat transfer of horizontal ground-freezing method in shield-driven tunneling," International Journal of Geomechanics, vol. 17, no. 10, Article ID 4017080, 2017.

[3] Y. Liu, Y. Cai, S. Huang, Y. Guo, and G. Liu, "Effect of water saturation on uniaxial compressive strength and damage degree of clay-bearing sandstone under freeze-thaw," Bulletin of Engineering Geology and the Environment, vol. 79, no. 4, pp. 2021-2036, 2020.

[4] L. Fan, C. Xu, and Z. Wu, "Effects of cyclic freezing and thawing on the mechanical behavior of dried and saturated sandstone," Bulletin of Engineering Geology and the Environment, vol. 79, no. 2, pp. 755-765, 2020.

[5] W. Ye and C. Li, "The consequences of changes in the structure of loess as a result of cyclic freezing and thawing," Bulletin of Engineering Geology and the Environment, vol. 78, no. 3, pp. 2125-2138, 2019.

[6] J. Xu, J. Ren, Z. Wang, S. Wang, and J. Yuan, "Strength behaviors and meso-structural characters of loess after freezethaw," Cold Regions Science and Technology, vol. 148, pp. 104-120, 2018.

[7] J. Xu, Y. Li, W. Lan, and S. Wang, "Shear strength and damage mechanism of saline intact loess after freeze-thaw cycling," Cold Regions Science and Technology, vol. 164, Article ID 102779, 2019.

[8] Z. Ding, M. Y. Zhang, X. J. Wei et al., "Experimental research on the microstructure of thawed soil after the subway construction of freezing method," Journal of Railway Engineering Society, vol. 33, no. 11, pp. 106-112, 2016.

[9] L. Han, G.-L. Ye, Y.-H. Li, X.-H. Xia, and J.-H. Wang, "In situ monitoring of frost heave pressure during cross passage construction using ground-freezing method," Canadian Geotechnical Journal, vol. 53, no. 3, pp. 530-539, 2016.

[10] J. Hu, W. Liu, Y. Pan, and H. Zeng, "Site measurement and study of vertical freezing wall temperatures of a large-diameter shield tunnel," Advances in Civil Engineering, vol. 2019, Article ID 8231458, 11 pages, 2019.

[11] E. Pimentel, S. Papakonstantinou, and G. Anagnostou, "Numerical interpretation of temperature distributions from three ground freezing applications in urban tunnelling," Tunnelling and Underground Space Technology, vol. 28, pp. 57-69, 2012.

[12] M. Vitel, A. Rouabhi, M. Tijani, and F. Guérin, "Modeling heat transfer between a freeze pipe and the surrounding ground during artificial ground freezing activitiesficial ground freezing activities," Computers and Geotechnics, vol. 63, pp. 99-111, 2015.

[13] D.-J. Zhao, Y.-M. Liu, Y.-H. Sun, Y. Zhao, and F.-T. Bai, "Experiments and simulations of underground artificial freezing with the use of natural cold resources in cold regionsficial freezing with the use of natural cold resources in cold regions," Building and Environment, vol. 87, pp. 224-233, 2015.

[14] H. Song, H. Cai, Z. Yao, C. Rong, and X. Wang, "Finite element analysis on 3D freezing temperature field in metro cross passage construction," Procedia Engineering, vol. 165, pp. $528-539,2016$.
[15] W. Fan and P. Yang, "Ground temperature characteristics during artificial freezing around a subway cross passage," Transportation Geotechnics, vol. 20, Article ID 100250, 2019.

[16] Y. Mei, C.-M. Hu, Y.-L. Yuan, X.-Y. Wang, and N. Zhao, "Experimental study on deformation and strength property of compacted loess," Geomechanics and Engineering, vol. 11, no. 1, pp. 161-175, 2016.

[17] Y. Mei, Y.-L. Li, X.-Y. Wang, J. Wang, and C.-M. Hu, "Statistical analysis of deformation laws of deep foundation pits in collapsible loess," Arabian Journal for Science and Engineering, vol. 44, no. 10, pp. 8347-8360, 2019.

[18] H. Wang, W. B. Zhu, and D. Y. Li, "Construction method and control measure for connecting passage in water - enriched sand bed," Journal of Railway Engineering Society, vol. 27, no. 9, pp. 82-87, 2010.

[19] Shanghai Press and Publication Administration, Technical Code for Crosspassage Freezing Method: DG/TJ09, Shanghai Press and Publication Administration, Shanghai, China, 2006, in Chinese.

[20] P. Menetrey and K. J. Willam, "Triaxial failure criterion for concrete and its generalization," Structural Journal, vol. 92, no. 3, pp. 311-318, 1995.

[21] G. Galli, A. Grimaldi, and A. Leonardi, “Three-dimensional modelling of tunnel excavation and lining," Computers and Geotechnics, vol. 31, no. 3, pp. 171-183, 2004.

[22] A. K. Verma and T. N. Singh, "Assessment of tunnel instability-a numerical approach," Arabian Journal of Geosciences, vol. 3, no. 2, pp. 181-192, 2010.

[23] H. Wang, C. X. Guo, Y. P. Wu et al., "Relationship between the frost-heaving coefficient and the frost-heaving rate of permafrost soils considering the ice water phase transformation based on elastic mechanics," Chinese Journal of Rock Mechanics and Engineering, vol. 37, no. 12, pp. 2839-2845, 2018.

[24] R. B. Peck, "Deep excavations and tunneling in soft ground," in Proceedings of the Proceedings of the 7th International Conference on Soil Mechanics and Foundation Engineering, pp. 225-229, Mexico City, Mexico, 1969.

[25] M. P. O'Reilly and B. M. New, Settlements above Tunnels in the United Kingdom: Their Magnitude and Prediction, Institution of Mining \& Metallurgy, London, UK, 1982.

[26] Y. L. Cui, A Concise Hand Book of Mine Construction Engineering, China Coal Industry Press, Beijing, China, 2003, in Chinese, 1th edition.

[27] J.-M. Konrad, "Freezing-induced water migration in compacted base-course materials," Canadian Geotechnical Journal, vol. 45, no. 7, pp. 895-909, 2008.

[28] J. Zhou, C. Wei, D. Li, and H. Wei, "A moving-pump model for water migration in unsaturated freezing soil," Cold Regions Science and Technology, vol. 104, pp. 14-22, 2014.

[29] O. Bonacci, S. Gottstein, and T. Roje-Bonacci, "Negative impacts of grouting on the underground karst environment," Ecohydrology, vol. 2, no. 4, pp. 492-502, 2009. 